\title{
The Role of KM in Enhancing AI Algorithms and Systems
}

\author{
Hani AlGhanem ${ }^{1}$, Mohammad Shanaa ${ }^{1}$, Said Salloum ${ }^{1,2, *}$, Khaled Shaalan ${ }^{1}$ \\ ${ }^{1}$ Faculty of Engineering \&IT, The British University in Dubai, 345015, United Arab Emirates \\ ${ }^{2}$ Research Institute of Sciences \& Engineering, University of Sharjah, 27272, United Arab Emirates
}

\begin{tabular}{l} 
A R T I C L E I N F O \\
\hline Article history: \\
Received: 24 June, 2020 \\
Accepted: 14 July, 2020 \\
Online: 28 July, 2020 \\
\hline Keywords: \\
Knowledge management \\
Artificial intelligence \\
AI algorithms
\end{tabular}

\section{Introduction}

Knowledge plays an essential role in the maintenance of organization business [1], as it can be explained as one of the most critical factors that companies need to maintain their business in the market [2]-[4], also knowledge considered as a valuable intangible resource. It includes all the ideas, concepts, data, technologies stored in the human brain [5]. Knowledge has many properties and can be summarized as 1) can be created by personnel, 2) dilatable, 3) can be saved in individuals brain or any other document storage or computerized storage, 4) can be stored in specific orders for easy of retrieving it when needed, 5) can be shared with others, 6) forgettable and can be lost [6]. Recently, the attention of KM has been evolved dramatically as many pieces of research, consultants, and specialists focus on organizational knowledge management in order to overcome the challenges that faced organizations [7], [8].

Knowledge management is considered a new domain for government institutes, which used to coordinate between all of the

${ }^{*}$ Corresponding Author: Said Salloum, University of Sharjah, UAE.

Tel: +971507679647 Email: ssalloum@sharjah.ac.ae

www.astesj.com

$\underline{\text { https://dx.doi.org/10.25046/aj050445 }}$ human resources, technological resources, organization structure, and environment to improve organization strategies [5]. Besides, $\mathrm{KM}$ exerted an effective role in educational practices [9]-[12]. While [13] collect the agreed definition of knowledge management as "creation, communication, and application of knowledge." Moreover, consider a vital tool to improve organizational processes. The primary purpose of KM is described by [14] "to improve the systematic handling of knowledge and potential knowledge within the organization". AI is the way to build a software program that can imitate the human brain in many mental procedures and processes, including learning, thinking, building perception, natural language processing, innovation, and complex issues resolution [15]. AI can be employed in many applications that required thinking and analysis, using AI tools such as statistical and mathematical methodologies to build computer understanding and machine learning in the same way as human thinking and acquiring knowledge. In their study of intelligent vehicles, they assert that the usefulness of feeding back the generated knowledge form the test result of smart vehicles to AI systems in order to improve it, so the AI system can learn more 


\section{H. AlGhanem et al. / Advances in Science, Technology and Engineering Systems Journal Vol. 5, No. 4, 388-396 (2020)}

and provide better results[10]. In [16] they assert on the importance of the data warehouse to store organizational knowledge, and these data warehouses play an essential role in the application of artificial intelligent in general and decision support systems in specific, furthermore, Data/open data is considered a booster for the Information technology industry [17].

This review study raises the following four research questions:

1. What are the primary knowledge management processes studied, and how it is impacting AI systems?

2. What are the leading AI algorithms and systems reviewed in the studies collected?

3. What research methods have been used in finding the relation between knowledge management processes and AI systems?

4. How active is the topic of knowledge management impact on AI during the last five years, across the research databases?

The remainder of the review is split as follows: Section 2 containing a literature review, research methodology discussed in section 3. Section 4 demonstrates the findings and results achieved from the in-depth analysis of the articles reviewed. Finally, the review is concluded in section 5 .

\section{Literature review}

Nobody could deny the role of information systems in our daily lives [18], [19]. Knowledge management plays a vital role in accelerating the wheels of information systems [20]-[22]. The initial show of knowledge management return to the $80 \mathrm{~s}$ as came along with AI and expert systems, then it spread out between businessmen, academics, and consultants, in the last ten year big companies like telecommunication has many success factors, and one of the critical factors is the knowledge that gained from employees experience, stakeholders, customers, and competitors. This knowledge provides the companies with a strategic and sustainable competitive advantage by building an organizational culture having active knowledge management in general and knowledge sharing in specific [23].

A study by [24] explains that knowledge management tools are used to help in knowledge generation, documentation, and sharing. $\mathrm{KM}$ tools are used to make managing the knowledge is easier by implementing IT technologies to create, organize, and share knowledge, which helps to improve organization operation. KM tools can be classified into four groups; the first one is tools to discover knowledge and to build the knowledge structure, which concentrates on the current knowledge and the existing one, and to make available in a well-structured format and easy to access by linking the information, ideas, and experiences. The second one is tools for knowledge processing, which can be defined as the workflow of how to deal with information and knowledge by filter, store, and analyze it. The third one is tools used for share and transfers the knowledge between individuals, which included organization local intranet or internet; furthermore, it can be extended to public online forums, wiki which make the organization issues resolving the environment having. The fourth and final one is tools used to analyzing and applying the knowledge, which includes a wide range of applications, including intelligent agents, expert systems, and many others that help in decision making.
After reviewing 20 styles of $\mathrm{KM}$ frameworks in the period 1991 to 2015, In [25] conclude a unified KM framework which includes the five primary processes, the first one is knowledge transfer that focuses how the knowledge and information are being moved from one individual/organization to another using interaction between people or organizations in a written or verbal way through traditional ways of using technological way. The second one is storing the knowledge in a suitable storage device, and nowadays it is stored electronically as documents or into databases; storing the knowledge is essential; because knowledge can be lost, especially the tacit knowledge. The third one is knowledge application, is the way how to get benefit from the stored knowledge and employ it to improve organization innovation, processes, performance to build a continuous competitive advantage, and this can be done using knowledge application software like expert system, intelligent agents, decision-making systems. The fourth one is knowledge creation, which is come by converting explicit and tacit using different ways like internalization, combination, externalization, socialization. Also, knowledge can be created by interviewing the experts and knowledge exchange between individuals or by documenting the organizational work procedure. The fifth and last one is knowledge acquisition; this is the process of getting knowledge from outside of the organization and uses it within the organization's knowledge base, like knowledge gained from customers, competitors, or suppliers.

Many tools can be used and present AI, such as Intelligent Agents, Business intelligence, gadgets dashboard, and expert systems [15]. While [26] define the intelligent agents as "an autonomous system that can obtain synergy effects by combining a practical user interface, on the one hand, and an intelligent system based on Artificial Intelligence, Neural Networks, and fuzzy theory, on the other hand.".

An intelligent agent is defined as a computer system that can understand the environment that its existence in and interact based on the received data and predefined rules [27]. Intelligent agents can be categorized into different groups; the first one is the collaborative or non-collaborative, the collaborative mean that intelligent agents do a sequence of operation that one agent starts after the previous one finish his task. The second one is the profitable economy agents, which focus on the stock market and online trading by doing automatic deals and decisions. The third one is online assistant agents that can learn from the user experience. While the fourth one is called mobile agents as it can be used over the internet, for example, it can play a role in load balancing on specific servers [26].

The concept of Business intelligence (BI) was first introduced in the 90s and nowadays become widely used mainly in business to support decision making (Watson, H.J. and Wixom, B.H., 2007). BI provides a user interface that enables users to analyze and drill down the data into the information to extract and useful knowledge and data that needed to help in tacking a decision using a friendly geographical interface including charts, aggregates, and statistics [28].

The expert system is known as the first kinds of AI Implementation and can be used on an organizational level or personality level. Usually, an expert system consists of a 


\section{H. AlGhanem et al. / Advances in Science, Technology and Engineering Systems Journal Vol. 5, No. 4, 388-396 (2020)}

knowledge base module which used to keep all information and data related to issues solving. While fact base module contains some categorized information about specific cases, usually it used to build the final result, explanation module, which provides the steps that used in order to reach a specific solution depending on facts/ knowledge base. Finally, a presentation module responsible for providing all data to end-users in a human-readable and structured format [15]. There are two significant modules of expert systems, which are 1) knowledge-base which can build using fuzzy or first-order logic. So expert systems can fit the electronic governments due to the nature of e-government problems [29]. So expert systems consider and an application of knowledge management as it helps in decision making and problem-solving [30].

Neural Networks, including ANN, RNN, and CNN, simulates the human neural nerves, and it uses learning from provided data and experiments to build the network model and to find the unseen patterns within these data. Neural Networks, including ANN, $\mathrm{RNN}$, and $\mathrm{CNN}$, considered a robust algorithm to predict and forecast cretin scenario cases [31]. Artificial neural networks and data mining work in parallel for the CRM system in order to generate knowledge about customers' behaviors and to predict their willingness to purchase specific items [32]. Additionally, in [33] study, they express the importance of using knowledge management in order to feed the AI system as it is essential for personal characterization, which used to improve public safety using the decision tree algorithm.

It is essential to having a $\mathrm{KM}$ feeding to AI systems, which can help to improve $\mathrm{AI}$ in call center domains by helping call center agents to find the best resolution for the caller and customer, but KM should have reliable data and source of information. Machine learning (ML) can be employed by reading the history of customer chat conversation and previously solved issues with customers to prepare suggested answers to be used by customer services representative with the ability to customize the prepared answers by ML[24].

According to a study by [34] use many AI algorithms and implement it in a knowledge management system specifically in knowledge extraction to predict Heart failure for patients, among nine classifiers, the results come by employing Random forests algorithm with a range between 10 to 100 trees. Also, in [35] within the same medical domain, they use various AI algorithms, and one of them is the random forests, which is defined as a group of random and parallel created decision trees. The output of this algorithm is considered the average of the output of all decision trees within the forest.

Based on the studies that exist in the literature, most of the reviews are focusing on the direct impact on the knowledge management process to AI systems and algorithms, despite the cost or the possibility of implementing the idea within the organizations. Ignoring other criteria like cost has a negative impact, as seen in one of the studies that, despite the positive effect of system output to enhance performance and data accuracy, the cost of implementing these systems was a significant obstacle to adopt it. These facts encourage us to study the researches available to highlight this missing point and to assist researchers in focusing more on the implementation and adoption of the relation.
Additionally, our study gives other available options for Knowledge Management processes, which can help in enhancing AI systems and algorithms.

\section{Methodology}

The systematic review provides a way to explorer all published papers, chapters, and articles to remove any biased conclusions [36]-[44]. While researches that do not consider a systematic way might lead to higher risk by selecting certain studies that support the author's point of view only and eliminate other points of view [45]. Also, Systematic review gives the reader the latest explored knowledge available in the entire literature for a specific research area or question [46]-[48].

A study by [49] summarize the process of systematic review in six steps. 1) Starting by specifying the research questions or the hypothesis that needs to be tested. 2) Then an inclusion/ exclusion criteria to be determined in order to filter the collected papers based on that criteria. 3) After that, a thorough search for all papers related to the research question to be collected from all available databases by defining the strategy and keywords for the search. 4) review all the retrieved papers from the previous step and evaluate the quality of the papers based on the title, abstract, or the conclusion; this step will eliminate all the un-related papers. 5) Data mining and extraction from the non-eliminated papers from the previous step using thorough reading and analysis of the paper according to research questions. 6) Finally, doing data analysis and answer the research questions providing shreds of evidence from the selected papers, and supported by literature review.

The systematic review is used to understand the impact of applying knowledge management processes in improving the decision making systems for health care [39]. The study utilizes a four steps approach to finalize the selected papers for the review. The steps used in the study succeeded in eliminating papers that were not related to the research questions. Additionally, the study explains in a table, the research methodology and findings from each of the selected papers. However, the table did not show the direction (positive/negative) for each paper and country of implementation as these details may impact the implementation of knowledge management in healthcare decision making systems if applied to countries with different rules and regulations.

Finally, the authors find that following the steps from [40], will help in achieving the paper goals.

Table 1: Inclusion and exclusion criteria.

\begin{tabular}{|l|l|}
\hline \multicolumn{1}{|c|}{ Inclusion } & \multicolumn{1}{c|}{ Exclusion } \\
\hline $\begin{array}{l}\text { Should be related to } \\
\text { knowledge management } \\
\text { Methodologies, processes, } \\
\text { or lifecycle. }\end{array}$ & Articles published before 2014. \\
\hline $\begin{array}{l}\text { Should be related to } \\
\text { artificial Intelligent } \\
\text { Algorithms, or Techniques. }\end{array}$ & $\begin{array}{l}\text { Related to Knowledge } \\
\text { management, but not linked to } \\
\text { Artificial Intelligent. }\end{array}$ \\
\hline $\begin{array}{l}\text { Should be related to the } \\
\text { government domain or } \\
\text { related to the general } \\
\text { domain (without specific } \\
\text { domain mentioned). }\end{array}$ & $\begin{array}{l}\text { Related to Artificial intelligence } \\
\text { but not linked to Knowledge } \\
\text { management. }\end{array}$ \\
\hline
\end{tabular}




\subsection{Inclusion/exclusion criteria}

For the collected paper, it filtered in or out based on certain criteria, which are summarized in Table 1.

So, the above Table 1 shows the criteria that need to be considered when preparing the papers for the systematic review, so the result after applying the inclusion and exclusion criteria will be a list of papers that will be used in this study.

\subsection{Data sources and search criteria}

In order to collect the papers that are considered in these systematic reviews, a list of keywords was used or a combination of it using "And" operations. These keywords are "Knowledge management", "Artificial intelligent", government, "Artificial Intelligence", "e-Government". These keywords were used in different publication databases, including "ArticleFirst", "Electronic Collections Online", "Emerald Group Publishing Limited", "Google Scholar", and "Worldcat". The total numbers of retrieved papers were 239 .the first exclusion based on the year of publication and all papers before 2014, so 109 papers were eliminated. Two papers were found as duplicated. The remaining papers were 130. After applying all criteria from the inclusion and exclusion table, the remaining number of papers is 16 . and listed in Table 2, which contain the source of the paper, details about knowledge management process, artificially intelligent algorithms or system, the research method that used in the paper, the country that targeted by the study, the target domain, the database that collected from and brief and summary about the paper and the main idea behind it.

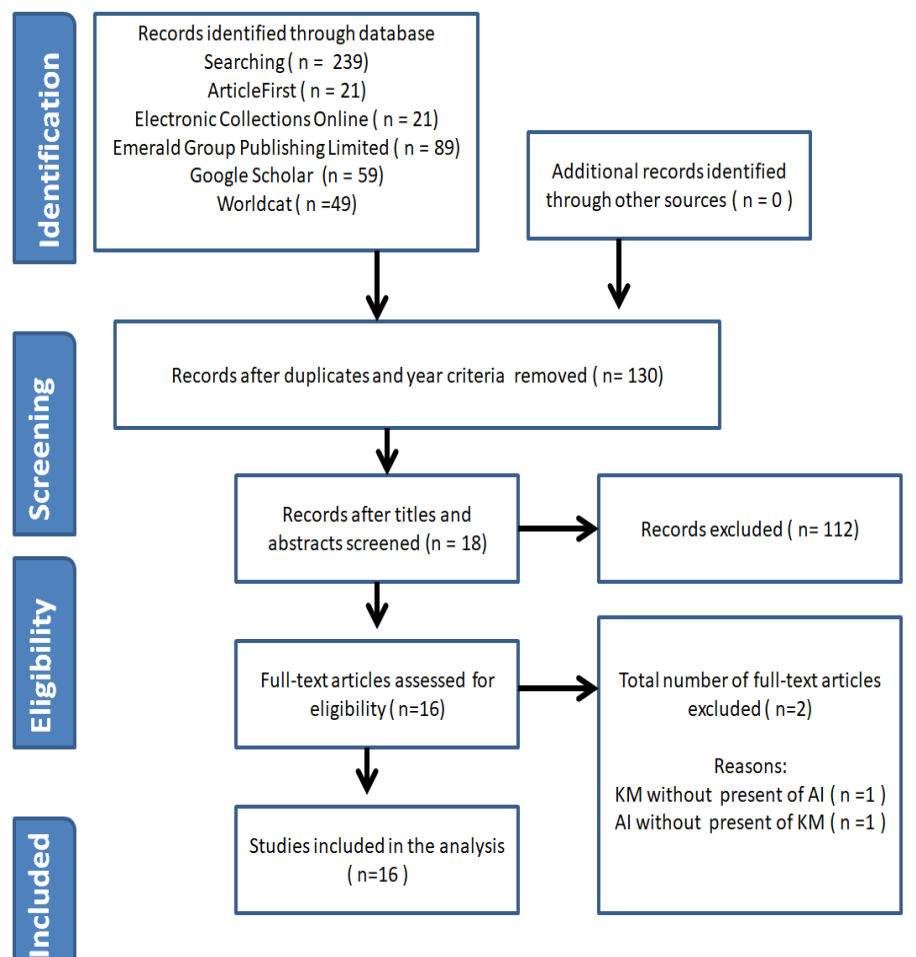

Figure 1: Process of selection papers.

Figure 1 shows the main phases of paper selection in systematic review starting by identifying the databases and collected numbers of each database; also, it explains that there are no additional sources of papers, from screening phase all duplicated papers and year criteria applied to filter out un-needed papers. The eligibility phase came to check the content of the papers if it fit and contain the research required info or not. Moreover, the final phase came to include the remaining papers in the study and analyze it

\subsection{Quality assessment}

In the systematic review, there is a concern about the quality of the collected papers, even inclusion and exclusion criteria applied, but it is not enough to check the quality of paper contents. A quality test should be conducted as strong evidence of good papers quality can tell how strong is the conclusion can be made [50]. So to check the quality of the papers, a quality assessment checklist was defined as shown in Table 2. For scoring purposes, there will be three values; if the answer to the question is yes, then the score will be 1 ; if the answer is no, then the score will be 0 ; if the answer is partially presented, then the score will be 0.5 .

Table 2: A quality assessment checklist.

\begin{tabular}{|c|l|}
\hline$\#$ & \multicolumn{1}{|c|}{ Question } \\
\hline 1 & Are the research aims clearly specified? \\
\hline 2 & $\begin{array}{l}\text { Are the Knowledge/KM considered by the study } \\
\text { clearly specified? }\end{array}$ \\
\hline 3 & Is the AI considered by the study clearly specified? \\
\hline 4 & Do the results add to the literature? \\
\hline 5 & $\begin{array}{l}\text { Does the study add to your knowledge or } \\
\text { understanding? }\end{array}$ \\
\hline
\end{tabular}

Based on the scoring criteria and Table 2, for each paper, a score between 0 to 5 . By applying the quality assessment for all the 16 papers, a result shows in Table 3, $\mathrm{P} 1$ to $\mathrm{P} 16$ is a list of papers in the same order of papers list in table 4 main table. The results show that all papers are in excellent quality, so all of the 16 papers will be included in the analysis.

Table 3: Quality assessment result.

\begin{tabular}{|c|c|c|c|c|c|c|c|}
\hline Source & Q1 & Q2 & Q3 & Q4 & Q5 & Total & \% \\
\hline P1 & 1 & 0.5 & 1 & 0.5 & 1 & 4 & $80 \%$ \\
\hline P2 & 1 & 1 & 1 & 1 & 1 & 5 & $100 \%$ \\
\hline P3 & 1 & 1 & 0.5 & 1 & 1 & 4.5 & $90 \%$ \\
\hline P4 & 1 & 0.5 & 1 & 1 & 1 & 4.5 & $90 \%$ \\
\hline P5 & 1 & 1 & 1 & 1 & 1 & 5 & $100 \%$ \\
\hline P6 & 1 & 1 & 0.5 & 1 & 1 & 4.5 & $90 \%$ \\
\hline P7 & 1 & 1 & 1 & 1 & 1 & 5 & $100 \%$ \\
\hline P8 & 0.5 & 1 & 1 & 1 & 1 & 4.5 & $90 \%$ \\
\hline P9 & 1 & 1 & 0.5 & 1 & 0.5 & 4 & $80 \%$ \\
\hline P10 & 0.5 & 0.5 & 1 & 1 & 1 & 4 & $80 \%$ \\
\hline P11 & 1 & 1 & 1 & 1 & 1 & 5 & $100 \%$ \\
\hline P12 & 1 & 1 & 0.5 & 1 & 1 & 4.5 & $90 \%$ \\
\hline P13 & 1 & 1 & 1 & 1 & 1 & 5 & $100 \%$ \\
\hline P14 & 1 & 1 & 1 & 1 & 1 & 5 & $100 \%$ \\
\hline P15 & 1 & 1 & 1 & 1 & 1 & 5 & $100 \%$ \\
\hline P16 & 1 & 1 & 1 & 1 & 1 & 5 & $100 \%$ \\
\hline
\end{tabular}




\subsection{Data coding and analysis}

The analysis section depends on the six steps suggested by [51] for a systematic review. In the initial phase, this paper analyzed the relationship and the quality of coded characteristics. Initially, the authors list the main Knowledge management processes for the papers reviewed. In addition to AI Algorithms and Systems, Research database (e.g., WorldCat, Emerald, and others), study direction (Positive, Negative, Neutral), Target Organization (public, private), and country. During the first analysis phase, authors excluded all papers which do not directly describe the impact of knowledge management on AI algorithms and systems. The authors analyzed all documents by dividing all studies between the authors and manually examine the articles. Secondly, the authors reviewed the papers on a high level and start excluding duplicate papers, and papers not on direct relation to this paper topic based on title and abstract screening. After that, the authors deep analyze the remaining researches and start to exclude papers that are not eligible based on a full review and quality assessment questions defined. Finally, 16 papers were selected as they match the quality criteria. Table 4 present the selected papers with the coding characteristics for each paper. The table reflects the analysis done for each paper in rows, by specifying the KM process discussed in the paper, the AI algorithm or system used, and the source research database. Additionally, the table stating the type of research methodology used in each study, the country research used within, and target type audience. Finally, the table illustrated the direction for the paper (Negative/Positive) and added the findings from each study.

Table 4: Analysis of knowledge management research articles with regard to AI algorithms and systems

\begin{tabular}{|c|c|c|c|c|c|}
\hline \# & Ref. & $\begin{array}{l}\text { KM } \\
\text { Process }\end{array}$ & $\begin{array}{l}\text { AI } \\
\text { Algorithm / } \\
\text { AI Systems }\end{array}$ & Method & Country \\
\hline P1 & [52] & $\begin{array}{l}\text { Knowledge } \\
\text { Application } \\
\text { /Decision } \\
\text { making }\end{array}$ & $\begin{array}{l}\text { Neural } \\
\text { Networks } \\
\text { including } \\
\text { ANN, RNN, } \\
\text { and CNN }\end{array}$ & Survey & USA \\
\hline $\mathrm{P} 2$ & [15] & $\begin{array}{l}\text { Knowledge } \\
\text { Discovery }\end{array}$ & $\begin{array}{l}\text { 1) Expert } \\
\text { Systems } \\
\text { 2) Multi- } \\
\text { agent } \\
\text { systems } \\
\text { 3) Business } \\
\text { Intelligence } \\
\text { 4) } \\
\text { Performanc } \\
\text { e } \\
\text { Dashboards }\end{array}$ & $\begin{array}{l}\text { Case } \\
\text { Study }\end{array}$ & Poland \\
\hline P3 & [53] & $\begin{array}{l}\text { Knowledge } \\
\text { Creation }\end{array}$ & $\begin{array}{l}\text { 1) Natural } \\
\text { Language } \\
\text { Processing } \\
\text { 2) Machine- } \\
\text { learning } \\
\text { techniques } \\
\text { 3) Human } \\
\text { intelligence }\end{array}$ & $\begin{array}{l}\text { Experim } \\
\text { ental }\end{array}$ & General \\
\hline P4 & [31] & $\begin{array}{l}\text { Knowledge } \\
\text { Application } \\
\text { /Decision } \\
\text { making }\end{array}$ & $\begin{array}{l}\text { Neural } \\
\text { Networks } \\
\text { including } \\
\text { ANN, RNN, } \\
\text { and CNN }\end{array}$ & $\begin{array}{l}\text { Intervie } \\
\text { ws and } \\
\text { Experim } \\
\text { ental }\end{array}$ & Iran \\
\hline
\end{tabular}

\begin{tabular}{|c|c|c|c|c|c|}
\hline P5 & [54] & $\begin{array}{l}\text { Knowledge } \\
\text { Creation }\end{array}$ & $\begin{array}{l}\text { AI in } \\
\text { General }\end{array}$ & $\begin{array}{l}\text { Experim } \\
\text { ental }\end{array}$ & China \\
\hline P6 & [55] & $\begin{array}{l}\text { Knowledge } \\
\text { Acquisition }\end{array}$ & $\begin{array}{l}\text { Ontology } \\
\text { and XML }\end{array}$ & $\begin{array}{l}\text { Experim } \\
\text { ental }\end{array}$ & Italy \\
\hline P7 & [29] & $\begin{array}{l}\text { Knowledge } \\
\text { Creation }\end{array}$ & $\begin{array}{l}\text { AI in } \\
\text { General }\end{array}$ & $\begin{array}{l}\text { Case } \\
\text { Study } \\
\end{array}$ & $\begin{array}{l}\text { Banglades } \\
\mathrm{h}\end{array}$ \\
\hline P8 & [33] & $\begin{array}{l}\text { Knowledge } \\
\text { Application } \\
\text { /Decision } \\
\text { making }\end{array}$ & $\begin{array}{l}\text { Decision } \\
\text { Trees C4.5 }\end{array}$ & $\begin{array}{l}\text { Experim } \\
\text { ental }\end{array}$ & Colombia \\
\hline P9 & [56] & $\begin{array}{l}\text { Knowledge } \\
\text { Application } \\
\text { /Decision } \\
\text { making }\end{array}$ & Chatbot & $\begin{array}{l}\text { Case } \\
\text { Study }\end{array}$ & General \\
\hline P10 & [57] & $\begin{array}{l}\text { 1) } \\
\text { Knowledge- } \\
\text { Creating, } \\
\text { 2) } \\
\text { Knowledge } \\
\text { Acquisition } \\
\text { 3) } \\
\text { Knowledge } \\
\text { Sharing }\end{array}$ & $\begin{array}{l}\text { Expert } \\
\text { Systems }\end{array}$ & $\begin{array}{l}\text { Literatur } \\
\text { e } \\
\text { Review }\end{array}$ & KSA \\
\hline P11 & [58] & $\begin{array}{l}\text { 1) } \\
\text { Knowledge } \\
\text { Acquisition } \\
\text { 2) } \\
\text { Knowledge } \\
\text { Sharing }\end{array}$ & $\begin{array}{l}\text { 1) Fuzzy } \\
\text { Logic } \\
\text { 2) Case- } \\
\text { based } \\
\text { reasoning }\end{array}$ & $\begin{array}{l}\text { Case } \\
\text { study }\end{array}$ & Taiwan \\
\hline P12 & [59] & $\begin{array}{l}\text { Knowledge } \\
\text { Acquisition }\end{array}$ & Fuzzy Logic & $\begin{array}{l}\text { Literatur } \\
\text { e } \\
\text { Review }\end{array}$ & Brazil \\
\hline P13 & [60] & $\begin{array}{l}\text { Knowledge } \\
\text { Acquisition }\end{array}$ & $\begin{array}{l}\text { 1) Neural } \\
\text { Networks } \\
\text { including } \\
\text { ANN, RNN, } \\
\text { and CNN } \\
\text { 2) Support } \\
\text { Vector } \\
\text { Machines } \\
\text { 3) Genetic } \\
\text { Algorithms } \\
\text { 4) Rough } \\
\text { sets } \\
\text { 5) Fuzzy } \\
\text { Systems }\end{array}$ & $\begin{array}{l}\text { Literatur } \\
\text { e } \\
\text { Review }\end{array}$ & General \\
\hline P14 & [61] & $\begin{array}{l}\text { Knowledge } \\
\text { Acquisition }\end{array}$ & $\begin{array}{l}\text { 1) Expert } \\
\text { System } \\
\text { 2) Deep } \\
\text { Learning }\end{array}$ & $\begin{array}{l}\text { Case } \\
\text { study }\end{array}$ & Australia \\
\hline P15 & [34] & $\begin{array}{l}\text { Knowledge- } \\
\text { Creating, }\end{array}$ & $\begin{array}{l}\text { Prediction } \\
\text { model }\end{array}$ & $\begin{array}{l}\text { Experim } \\
\text { ental } \\
\text { and } \\
\text { compari } \\
\text { son } \\
\text { study }\end{array}$ & Greece \\
\hline P16 & [35] & $\begin{array}{l}\text { Knowledge- } \\
\text { Creating, }\end{array}$ & $\begin{array}{l}\text { Prediction } \\
\text { model }\end{array}$ & $\begin{array}{l}\text { Experim } \\
\text { ental }\end{array}$ & $\begin{array}{l}\text { Banglades } \\
\mathrm{h}\end{array}$ \\
\hline
\end{tabular}

\section{Results and discussion}

This systematic review is summarizing 16 articles published between 2014 and 2019 in Google scholar, Emerald, and WorldCat databases on regards to the impact of knowledge management processes in improving AI systems. The findings of this review discussed the following five questions: 
4.1. RQ1: What are the primary knowledge management processes studied, and how it is impacting AI systems?

Different studies were done to investigate the impact of knowledge management processes in enhancing the AI systems and algorithms. Table 5 describes the knowledge management processes involved in the study captured, and the frequency of using the method in each study. It is noticeable that knowledge acquisition is the most common processes used to enhance AI systems $(\mathrm{N}=6)$, followed by both knowledge creation and knowledge application/decision-making process $(\mathrm{N}=6)$, knowledge sharing $(\mathrm{N}=2)$, and Knowledge discovery with the least number of studies $(\mathrm{N}=1)$. Referring to Table 4 , it seems that knowledge application and decision-making processes have a positive impact on Neural Networks, including ANN, RNN, and CNN [31], Decision Trees [33], and Chatbots [56]. On the other hand, [52] argued that knowledge management application and decision making could have some negative impact on Neural Networks, including ANN, RNN, and CNN, in some applications.

Table 5: Knowledge management processes in the studies reviewed.

\begin{tabular}{|c|c|c|c|c|c|}
\hline & & & & \\
\hline & & & & \\
\hline
\end{tabular}

Additionally, it has been noticed that the Knowledge creation process has a positive impact on Natural Language Processing, Machine Learning, Human Intelligence [54], on Expert Systems [57], and on AI algorithms in general [29], [62].

Furthermore, the most knowledge management process impacting the AI systems as per the collected studies are knowledge acquisition and knowledge creation, as it is affecting Fuzzy Logic systems [58]-[60], Expert systems [57], [61], Neural Networks including ANN, RNN, and CNN Support Vector www.astesj.com
Machines, Genetic Algorithms, Rough sets [60], Deep Learning [61], Ontology and XML [55], and case-based reasoning [58]. Also, Knowledge Discovery seems to have a positive impact on Expert Systems, Multi-agent systems, Business Intelligence, Performance Dashboards [15]. Finally, the Knowledge Sharing process has a positive impact on Expert systems [57], Fuzzy Logic, and Case-based reasoning [58].

\subsection{RQ2: What are the leading AI algorithms and systems reviewed in the studies collected?}

Referring to Figure 2, it is noticeable that Expert systems, Neural Networks including ANN, RNN and CNN, and Fuzzy logic algorithms are taking the lead in the number of studies collected $(\mathrm{N}=3)$, followed by general AI study $(\mathrm{N}=2)$, and finally, other AI algorithms and Systems, Genetic Algorithms, Rough sets, Case-based reasoning, Human Intelligence, Machine Learning techniques, Chatbot, Decision Tree, Ontology and XML, Natural Language Processing, Performance Dashboards, Business Intelligence and Multi-language system $(\mathrm{N}=1)$.

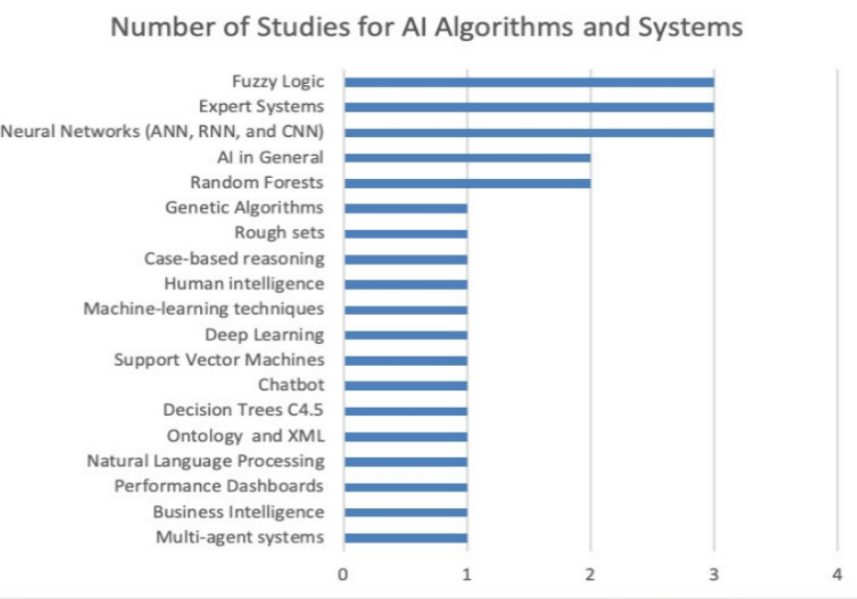

Figure 2: Number of Studies for AI Algorithms and systems.

\subsection{RQ3: What research methods have been used in finding the relation between knowledge management processes and AI systems?}

Analyzing Table 4 shows multiple research methods been used to find the relation between knowledge management processes, and AI algorithms and systems. Studies use Survey, Case Study, Experimental, Interviews, and Literature Review to perform the required analysis. Figure 3 presents the percentage and number of studies for each methodology. The experimental method takes the lead with seven studies with $44 \%$. Followed by Case Study with five studies and $33 \%$, followed by Literature Review with three studies and $18 \%$, and finally, the lowest two methods used are surveys and interviews with one research each and $6 \%$.

\subsection{RQ4: How active is the topic of knowledge management impact on AI during the last five years, across the research databases?}

Looking to the year of publication, and by analyzing Figure 4, we notice a drop in the number of researches studied the relationship between knowledge management and AI algorithms and systems since 2014. The highest number of papers was in 2014 $(\mathrm{N}=5)$, then from 2015 to 2017 there with the same number of researches $(\mathrm{N}=2)$, followed by $2018(\mathrm{~N}=2)$, and finally in 2019 increased to two pieces of research $(\mathrm{N}=3)$. 


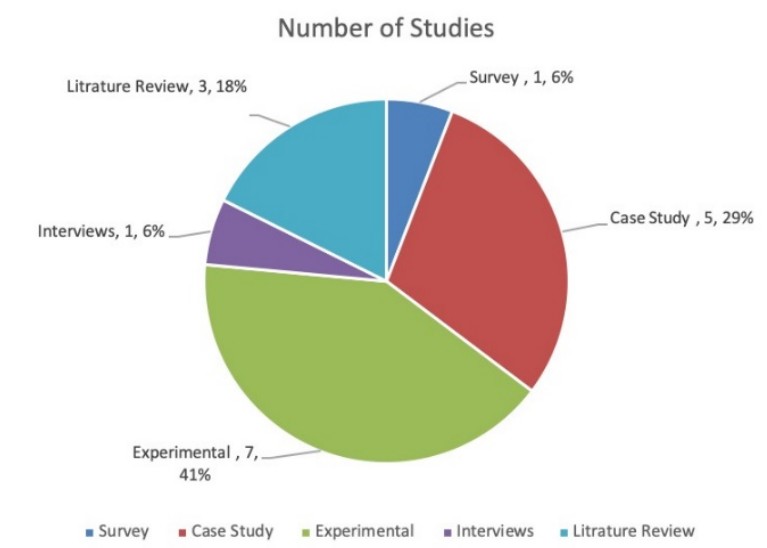

Figure 3: Research Methodology

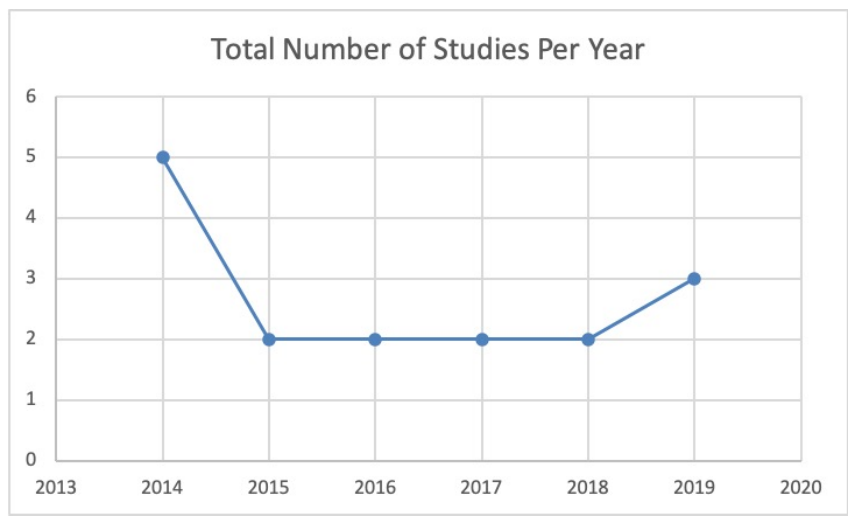

Figure 4: Total number of studies per year

Figure 5 shows how the Worldcat database is popular in having this topic as it has at least one paper every year from 2014 to 2019. The analysis indicates that Worldcat and Emerald have the top number of studies in $2014(\mathrm{~N}=2)$, followed by Google scholar $(\mathrm{N}$ $=1$ ). In 2015, and 2016, Worldcat was the only database with studies related to the topic. In 2017, both Worldcat and Emerald had one research and appeared on both years.while in 2018, both Worldcat and google scholar database with one study for each related to the topic. Finally, in 2019, Worldcat, Emerald, and google Scholar had one research and appeared in each.

Number of Studies per Database in each Year

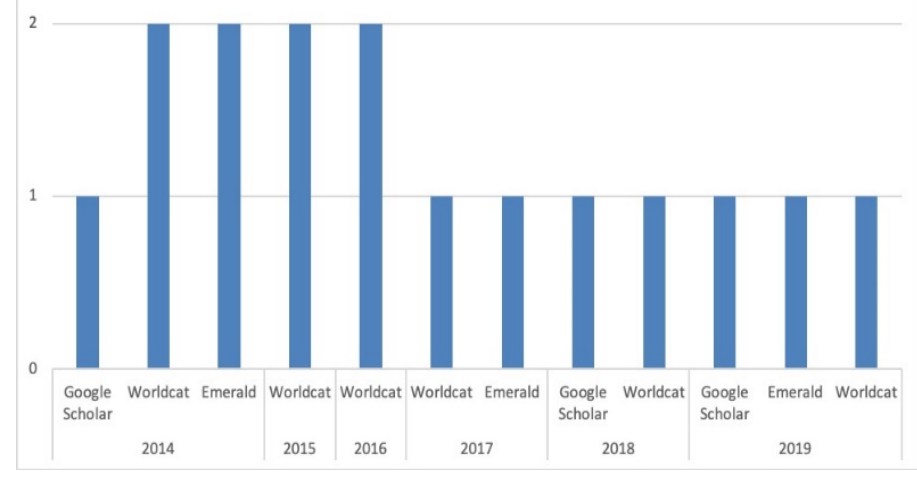

Figure 5: Number of studies per database in each year
Figure 6 describes the relationship between Knowledge management processes and the AI systems and algorithms that can be enhanced or impacted. This is also aligned with the previous discussion of the impact of knowledge acquisition on more number of AI systems and algorithms. Knowledge acquisition can passivity enhance Neural Networks, including ANN, RNN and CNN, Support Vector Machines, Genetic Algorithms, and rough sets, as also described in the study done by [60]. Both [58], [60] also agree that Knowledge acquisition can enhance Fuzzy Systems. Additionally, [61] added that knowledge acquisition could improve Expert systems and Deep learning by having a training way for the algorithms to enhance the outputs. Finally, based on Figure 4, we notice that the number of researches done for the relation between $\mathrm{KM}$ and $\mathrm{AI}$ systems is decreasing each year, comparing to the studies done in 2014.

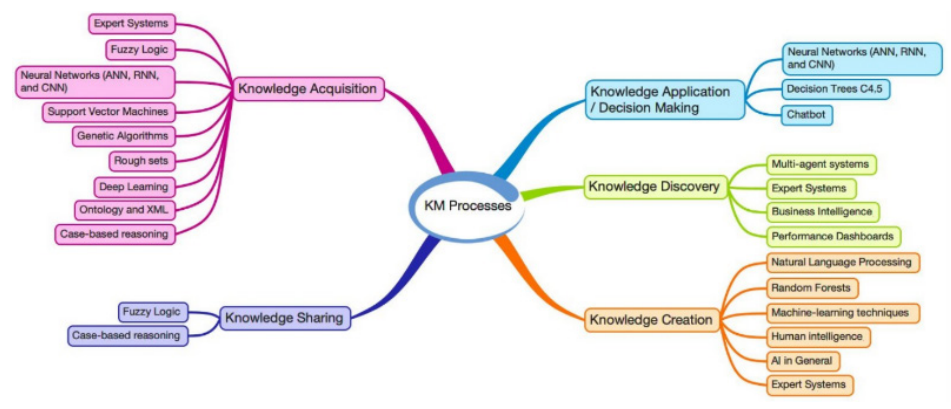

Regarding managerial insight, this paper provides a clear understanding of how each stage of knowledge management plays a role in enhancing AI Algorithms. Furthermore, this paper provides Practitioners, including software solutions architectures, digital transformation framework designers, and knowledge management, a solid base to get benefits from their knowledge management and employee the right $\mathrm{AI}$ algorithms to increase the benefits by using the right algorithms at the right KM stage.

\section{Conclusion}

The role of Knowledge Management processes in improving $\mathrm{AI}$ algorithms and systems was discussed in multiple studies. The paper used systematic review as an approach to determine the relationship between KM and how it affects AI systems and algorithms. This paper followed the six steps summarized by [51], to apply for a systematic review of selected papers. As a result, 16 papers were selected as they fit the requirements and selection criteria defined by the authors. Applying the quality assessment questions on all reviewed papers helped in filtering only highquality researches, which discussed the selected topic. However, and in some scenarios, authors need to be careful while putting the filtering questions as it could lead to bias in selecting papers based on the expected outcome, not the real results. On the other hand, this paper agreed that knowledge acquisition has a positive impact on enhancing Deep learning and Expert systems related to recordkeeper knowledge management in Australia, which increases the job inside offices [61].

In reference to Table 5, an analysis was done to classify the studies referring to Knowledge Management processes in enhancing AI algorithms and systems. It is noticeable that knowledge acquisition is the most common process to improve AI systems. This is in alignment with the studies done by [60], [61], which agree on the positive impact of knowledge acquisition on different AI systems and algorithms. Previous Knowledge management process papers studied the relation with AI systems 


\section{H. AlGhanem et al. / Advances in Science, Technology and Engineering Systems Journal Vol. 5, No. 4, $388-396$ (2020)}

and algorithms and focusing on specific AI system or algorithm. In this study, we tried to show the link between KM and AI systems looking from the higher picture, and showing that some KM processes can work not only for specific AI algorithms or methods, but it can also help in improving other AI algorithms. This can help researchers to identify other options to enhance an AI system by checking multiple options for a more cost-effective way if the current process used is having high implementation costs. Analysis finding illustrates the impact of knowledge management acquisition as the most used process to enhance the different type of AI systems and Algorithms. It also highlights that knowledge creation is the second option for improving AI systems. The analysis also shows that although some KM processes like knowledge application may have a positive impact on performance and data accuracy, it can have a negative impact on implementation due to high-cost requirements [52]. This research can suggest other KM processes as an option to achieve the required objectives, which may have less cost for implementations.

The limit of this study was on the implementation cost related to $\mathrm{KM}$ processes within AI systems as it will defer from an organization to another, based on the requirements and objectives required to achieve. Another limitation was due to the small number of studies done to find the relation between KM and AI systems, which limited the study outputs and may affect results accuracy. Future research may extend and improve the result of this research by increasing the number of databases that may have more studies related to the topic. Additionally, future researches can add a quality assessment question during the filtering steps to identify the degree or weight for the improvement in percentage; each KM process can give to AI algorithms and systems. For example, researches can highlight the results of how much improvement can KM process like knowledge acquisition give for AI Algorithm like Support Vector Machines. Furthermore, a detailed recommendation table can be created to highlight the best $\mathrm{KM}$ processes that can be used for each AI algorithm or system with expected improvement percentage and cost. Finally, this paper can be used as a foundation to prepare a comprehensive mapping table for the KM processes used to improve AI algorithms and systems.

It is beyond the scope of this paper to examine the actual implementation of the $\mathrm{KM}$ roles on $\mathrm{AI}$ algorithms, but it is recommended to make a real case study for an organization that has an existing knowledge management system or need to build a new knowledge management system. Moreover, to check how the theoretical results are supported in a practical case study.

\section{Acknowledgment}

This work is a part of a project undertaken at the British University in Dubai.

\section{References}

[1] S. A. Salloum, M. Al-Emran, and K. Shaalan, "The Impact of Knowledge Sharing on Information Systems: A Review," in 13th International Conference, KMO 2018, 2018. https://doi.org/10.1007/978-3-319-95204$\underline{8} 9$

[2] F. O. Omotayo and M. O. Salami, "Use of Social Media for Knowledge Sharing Among Students," Asian J. Inf. Sci. Technol., 8(2), 65-75, 2018.

[3] K. S. Ahlam Wahdan, Sendeyah Hantoobi, Said A. Salloum, "A systematic review of text classification research based ondeep learning models in Arabic language," Int. J. Electr. Comput. Eng., 10(6), 6629-6643, 2020. http://doi.org/10.11591/ijece.v10i6.pp\%25p

[4] S. S. B Al Kurdi, M Alshurideh, "Investigating a theoretical frameworkforelearning technology acceptance," Int. J. Electr. Comput. Eng., 10(6), 6484 6496, 2020. http://doi.org/10.11591/ijece.v10i6.pp\%25p
[5] P. López-Portillo, V. González, E. René, R. Hidalgo, and J. Alberto, "Knowledge management metrics for Public Organizations: A literature review-based proposal," arXiv Prepr. arXiv1609.09541, 2016. https://arxiv.org/abs/1609.09541

[6] S. Satyanarayan and G. Azumah, "Operationalisation of knowledge management practices in r\&d activity in multinational organisations," in Proceedings of the 12th Management International Conference: Managing Sustainability, Portorož, Slovania), 23-26, 2011.

[7] H. A. Nasiruzzaman, R. Qudaih, and D. Ahmad, "Project success and knowledge management $(\mathrm{km})$ practices in Malaysian institution of higher learning (IHL)," J. Educ. Vocat. Res., 4(5), 159-164, 2013. https://doi.org/10.22610/jevr.v4i5.114

[8] C. Rusuli, R. Tasmin, J. Takala, and H. Norazlin, "Knowledge Management Process At Malaysian University Libraries: A Review," Int. J. Soc. Sci.), 116., 2012

[9] M. A. Arpaci, I., Al-Emran, M., Al-Sharafi, "The impact of knowledge management practices on the acceptance of Massive Open Online Courses (MOOCs) by engineering students: A cross-cultural comparison, Telematics and Informatics.," 2020. https://doi.org/10.1016/j.tele.2020.101468

[10] M. Al-Emran and V. Mezhuyev, "Examining the Effect of Knowledge Management Factors on Mobile Learning Adoption Through the Use of Importance-Performance Map Analysis (IPMA)," in International Conference on Advanced Intelligent Systems and Informatics), 449-458, 2019. https://doi.org/10.1007/978-3-030-31129-2 41

[11] M. Al-Emran, V. Mezhuyev, and A. Kamaludin, "An Innovative Approach of Applying Knowledge Management in M-Learning Application Development: A Pilot Study," Int. J. Inf. Commun. Technol. Educ., 15(4), 94-112, 2019. DOI: 10.4018/IJICTE.2019100107

[12] M. Al-Emran, V. Mezhuyev, and A. Kamaludin, "Towards a conceptual model for examining the impact of knowledge management factors on mobile learning acceptance," Technol. Soc., 2020. https://doi.org/10.1016/j.techsoc.2020.101247

[13] W. Bodrow and V. Magalashvili, "It-Based Purpose-Driven Knowledge Visualization.," in ICSOFT (PL/DPS/KE/MUSE)), 194-197, 2007.

[14] P. Heisig, "Harmonisation of knowledge management-comparing $160 \mathrm{KM}$ frameworks around the globe," J. Knowl. Manag., 13(4), 4-31, 2009. DOI: https://doi.org/10.1108/13673270910971798

[15] P. Ziuziański, M. Furmankiewicz, and A. Sołtysik-Piorunkiewicz, "E-health artificial intelligence system implementation: case study of knowledge management dashboard of epidemiological data in Poland," Int. J. Biol. Biomed. Eng., 8), 164-171, 2014.

[16] H. R. Nemati, D. M. Steiger, L. S. Iyer, and R. T. Herschel, "Knowledge warehouse: an architectural integration of knowledge management, decision support, artificial intelligence and data warehousing," Decis. Support Syst., 33(2), 143-161, 2002. https://doi.org/10.1016/S0167-9236(01)00141-5

[17] H. AlGhanem, A. Mustafa, and S. Abdallah, "Knowledge and Human Development Authority in Dubai (KHDA) Open Data: What Do Researchers Want?," in European, Mediterranean, and Middle Eastern Conference on Information Systems), 58-70, 2019,. https://doi.org/10.1007/978-3-03044322-1 5

[18] C. Mhamdi, M. Al-Emran, and S. A. Salloum, Text mining and analytics: A case study from news channels posts on Facebook, 740. 2018. https://doi.org/10.1007/978-3-319-67056-0_19

[19] M. Al-Emran, S. Zaza, and K. Shaalan, "Parsing modern standard Arabic using Treebank resources," in 2015 International Conference on Information and Communication Technology Research, ICTRC 2015, 2015. DOI: $10.1109 /$ ICTRC.2015.7156426

[20] M. Al-Emran and T. Teo, "Do knowledge acquisition and knowledge sharing really affect e-learning adoption? An empirical study," Educ. Inf. Technol., 2019. https://doi.org/10.1007/s10639-019-10062-w

[21] M. Al-Emran, V. Mezhuyev, A. Kamaludin, and M. AlSinani, "Development of M-learning Application based on Knowledge Management Processes," in 2018 7th International conference on Software and Computer $\begin{array}{lll}\text { Applications } & \text { (ICSCA 2018), }\end{array}$ https://doi.org/10.1145/3185089.3185120

[22] M. Al-Emran, V. Mezhuyev, and A. Kamaludin, "Students' Perceptions towards the Integration of Knowledge Management Processes in M-learning Systems: A Preliminary Study," Int. J. Eng. Educ., 34(2), 371-380, 2018. https://dialnet.unirioja.es/servlet/articulo? codigo $=6872062$

[23] S. Banerjee, "Knowledge Management and Organizational Performance: The Case of a Telecommunication Organization in India.", 2018.

[24] S. Al-Hawamdeh, "Knowledge management: re-thinking information management and facing the challenge of managing tacit knowledge," Inf Res., 8(1), 1-8, 2002.

[25] M. M. Shongwe, "An analysis of knowledge management lifecycle 395 
frameworks: Towards a unified framework," Electron. J. Knowl. Manag., 14(3, p. 140, 2016.

[26] D. S. Kim, C. S. Kim, and K. W. Rim, "Modeling and design of intelligent agent system," Int. J. Control. Autom. Syst., 1(2), 257-261, 2003.

[27] D. Foster, C. McGregor, and S. El-Masri, "A survey of agent-based intelligent decision support systems to support clinical management and research," in proceedings of the 2nd international workshop on multi-agent systems for medicine, computational biology, and bioinformatics), 16-34, 2005.

[28] C. M. Olszak and E. Ziemba, "Approach to building and implementing business intelligence systems," Interdiscip. J. Information, Knowledge, Manag., 2(1), 135-148, 2007.

[29] M. S. Hossain, P. Zander, M. S. Kamal, and L. Chowdhury, "Belief-rulebased expert systems for evaluation of e-government: a case study," Expert Syst., 32(5), 563-577, 2015. https://doi.org/10.1111/exsy.12110

[30] H. Vacik, C. Torresan, T. Hujala, C. Khadka, and K. Reynolds, "The role of knowledge management tools in supporting sustainable forest management," For. Syst., 22(3), 442-455, 2013.

[31] A. Azadeh, K. Darivandi Shoushtari, M. Saberi, and E. Teimoury, "An Integrated artificial neural network and system dynamics approach in support of the viable system model to enhance industrial intelligence: The case of a large broiler industry," Syst. Res. Behav. Sci., 31(2), 236-257, 2014. https://doi.org/10.1002/sres.2199

[32] H. Y. Lam, G. T. S. Ho, C.-H. Wu, and K. L. Choy, "Customer relationship mining system for effective strategies formulation," Ind. Manag. Data Syst., 114(5), 711-733, 2014. https://doi.org/10.1108/IMDS-08-20130329 Download as .RIS

[33] V. H. Masías, M. A. Valle, J. J. Amar, M. Cervantes, G. Brunal, and F. A. Crespo, "Characterising the Personality of the Public Safety Offender and Non-offender using Decision Trees: The Case of Colombia," J. Investig. Psychol. Offender Profiling, 13(3), 198-219, 2016. https://doi.org/10.1002/jip.1451

[34] E. E. Tripoliti et al., "HEARTEN KMS-A knowledge management system targeting the management of patients with heart failure," J. Biomed. Inform., 94, p. 103203, 2019. https://doi.org/10.1016/j.jbi.2019.103203

[35] N. Nahar and F. Ara, "Liver disease prediction by using different decision tree techniques," Int. J. Data Min. Knowl. Manag. Process, 8(2), 1-9, 2018.

[36] S. A. S. Salloum and K. Shaalan, "Investigating students' acceptance of Elearning system in Higher Educational Environments in the UAE: Applying the Extended Technology Acceptance Model (TAM)." The British University in Dubai, 2018.

[37] S. A. Salloum, A. Qasim Mohammad Alhamad, M. Al-Emran, A. Abdel Monem, and K. Shaalan, "Exploring students' acceptance of e-learning through the development of a comprehensive technology acceptance model," IEEE Access, 7, 2019. DOI: 10.1109/ACCESS.2019.2939467

[38] S. F. S. Alhashmi, M. Alshurideh, B. Al Kurdi, and S. A. Salloum, "A Systematic Review of the Factors Affecting the Artificial Intelligence Implementation in the Health Care Sector," in Joint European-US Workshop on Applications of Invariance in Computer Vision), 37-49, 2020. https://doi.org/10.1007/978-3-030-44289-7_4

[39] S. K. Al Mansoori S., Salloum S.A., "The Impact of Artificial Intelligence and Information Technologies on the Efficiency of Knowledge Management at Modern Organizations: A Systematic Review.," Al-Emran M., Shaalan K., Hassanien A. Recent Adv. Intell. Syst. Smart Appl. Stud. Syst. Decis. Control. vol 295. Springer, Cham, 2021. https://doi.org/10.1007/978-3-030-47411999

[40] S. K. Areed S., Salloum S.A., "The Role of Knowledge Management Processes for Enhancing and Supporting Innovative Organizations: A Systematic Review.," Al-Emran M., Shaalan K., Hassanien A. Recent Adv. Intell. Syst. Smart Appl. Stud. Syst. Decis. Control. vol 295. Springer, Cham, 2021. https://doi.org/10.1007/978-3-030-47411-9_8

[41] S. K. AlShuweihi M., Salloum S.A., "Biomedical Corpora and Natural Language Processing on Clinical Text in Languages Other Than English: A Systematic Review.," Al-Emran M., Shaalan K., Hassanien A. Recent Adv. Intell. Syst. Smart Appl. Stud. Syst. Decis. Control. vol 295. Springer, Cham, 2021. https://doi.org/10.1007/978-3-030-47411-9 27

[42] S. K. Almansoori A., AlShamsi M., Salloum S.A., "Critical Review of Knowledge Management in Healthcare.," Al-Emran M., Shaalan K., Hassanien A. Recent Adv. Intell. Syst. Smart Appl. Stud. Syst. Decis. Control. vol 295. Springer, Cham, 2021. https://doi.org/10.1007/978-3-030-474119 6

[43] S. K. Habeh O., Thekrallah F., Salloum S.A., "Knowledge Sharing Challenges and Solutions Within Software Development Team: A Systematic Review.," Al-Emran M., Shaalan K., Hassanien A. Recent Adv. Intell. Syst. Smart Appl. Stud. Syst. Decis. Control. vol 295. Springer, Cham,
2021. https://doi.org/10.1007/978-3-030-47411-9 7

[44] S. K. Yousuf H., Lahzi M., Salloum S.A., "Systematic Review on Fully Homomorphic Encryption Scheme and Its Application.," Al-Emran M., Shaalan K., Hassanien A. Recent Adv. Intell. Syst. Smart Appl. Stud. Syst. Decis. Control. vol 295. Springer, Cham, 2021. https://doi.org/10.1007/9783-030-47411-9 29

[45] R. French and P. Brocklehurst, "The effect of pregnancy on survival in women infected with HIV a systematic review of the literature and metaanalysis," BJOG An Int. J. Obstet. Gynaecol., 105(8), 827-835, 1998. https://doi.org/10.1111/j.1471-0528.1998.tb10226.x

[46] D. M. Rousseau, J. Manning, and D. Denyer, "11 Evidence in management and organizational science: assembling the field's full weight of scientific knowledge through syntheses," Acad. Manag. Ann., 2(1), 475-515, 2008. https://doi.org/10.5465/19416520802211651

[47] N. Al-Qaysi, N. Mohamad-Nordin, and M. Al-Emran, "Employing the technology acceptance model in social media: A systematic review," Educ. Inf. Technol.), 1-42, 2020. https://doi.org/10.1007/s10639-020-10197-1

[48] M. Fatehah, V. Mezhuyev, and M. Al-Emran, "A Systematic Review of Metamodelling in Software Engineering," in Recent Advances in Intelligent Systems and Smart Applications), 3-27, Springer, 2021. https://doi.org/10.1007/978-3-030-47411-9_1

[49] F. F. Tránsito, M. R. Helena, J. G. P. Francisco, and A. M. V. José, "The systematic review of literature in LIS: An approach," in ACM International Conference Proceeding Series, 02-04-Nove), 291-298, 2016. https://doi.org/10.1145/3012430.3012531

[50] L. Victor, "Systematic reviewing," Soc. Res. Updat., 54(1), 1-4, 2008.

[51] T. Ferreras Fernández, H. Martín-Rodero, F. J. García-Peñalvo, and J. A. Merlo Vega, "The systematic review of literature in LIS: an approach," 2016. https://doi.org/10.1145/3012430.3012531

[52] O. Alsetoohy, B. Ayoun, S. Arous, F. Megahed, and G. Nabil, "Intelligent agent technology: what affects its adoption in hotel food supply chain management?," J. Hosp. Tour. Technol., 2019. https://doi.org/10.1108/JHTT-01-2018-0005

[53] X. Liu, C. Guo, and L. Zhang, "Scholar metadata and knowledge generation with human and artificial intelligence," J. Assoc. Inf. Sci. Technol., 65(6), 1187-1201, 2014. https://doi.org/10.1002/asi.23013

[54] L. Li et al., "Artificial intelligence test: a case study of intelligent vehicles," Artif. Intell. Rev., 50(3), 441-465, 2018. https://doi.org/10.1007/s10462$\underline{018-9631-5}$

[55] G. Boella, L. Di Caro, L. Humphreys, L. Robaldo, P. Rossi, and L. van der Torre, "Eunomos, a legal document and knowledge management system for the web to provide relevant, reliable and up-to-date information on the law," Artif. Intell. Law, 24(3), 245-283, 2016. https://doi.org/10.1007/s10506016-9184-3

[56] O. Smilansky, "The Real Benefits of Artificial Intelligence:Adding AI to the contact center enables rapid information retrieval, leading to a better experience for both agents and customers," Cust. Relatsh. Manag., 21 (11)), 28-31, 2017.

[57] A. Y. Al-Aama, "Technology knowledge management (TKM) taxonomy: using technology to manage knowledge in a Saudi municipality," Vine, 44(1), 2-21, 2014. https://doi.org/10.1108/VINE-12-2012-0052

[58] K. L. T. Choy et al., "An intelligent case-based knowledge management system for quality improvement in nursing homes," VINE J. Inf. Knowl. Manag. Syst., 48(1), 103-121, 2018. https://doi.org/10.1108/VJIKMS-012017-0001

[59] A. Sheffer Corrêa, A. de Assis Mota, L. Toledo Moreira Mota, and P. Luiz Pizzigatti Corrêa, "A fuzzy rule-based system to assess e-government technical interoperability maturity level," Transform. Gov. People, Process Policy, 8(3), 335-356, 2014. https://doi.org/10.1108/TG-08-2013-0028

[60] H. M. Said and A.-B. M. Salem, "Exploiting Computational intelligence Paradigms in e-Technologies and Activities," Procedia Comput. Sci., 65), 396-405, 2015.

[61] G. Rolan, G. Humphries, L. Jeffrey, E. Samaras, T. Antsoupova, and K. Stuart, "More human than human? Artificial intelligence in the archive," $\begin{array}{llll}\text { Arch. Manuscripts, } & \text { 47(2), 179-203, } 2019 .\end{array}$ https://doi.org/10.1080/01576895.2018.1502088

[62] Z. Li, W. M. Wang, G. Liu, L. Liu, J. He, and G. Q. Huang, "Toward open manufacturing: A cross-enterprises knowledge and services exchange framework based on blockchain and edge computing," Ind. Manag. Data Syst., 118(1), 303-320, 2018. 